\title{
Identification of staphylococcal and streptococcal causes of bovine mastitis using 16S-23S rRNA spacer regions
}

\author{
Päivi Forsman, ${ }^{1}$ Anu Tilsala-Timisjărvi' and Tapani Alatossava ${ }^{1,2}$
}

Author for correspondence: Päivi Forsman. Tel: +358 8553 1790. Fax: +358 85531061. e-mail: forsman@cypress.csc.fi

\begin{abstract}
Bovine mastitis is caused mainly by certain Staphylococcus and Streptococcus species. The sequences of the 16S-235 rRNA spacer regions were determined for the nine species which cause mastitis: Staphylococcus aureus, Staphylococcus chromogenes, Staphylococcus epidermidis, Staphylococcus hyicus, Staphylococcus simulans, Staphylococcus xylosus, Streptococcus agalactiae, Streptococcus dysgalactiae and Streptococcus uberis. Significant variation was found between the spacer sequences of different species with the lengths of the spacers varying from 240 to $461 \mathrm{bp}$. Between genera the spacers shared only short conserved regions (8-9 bp) and within genera the sequence identities varied from 53 to $85 \%$. This variation made it possible to construct specific primer pairs for these species and genera. The specificities of these primers were tested with 25 bacterial species and 51 isolates from cattle with clinical mastitis. The DNA-based identification of the mastitis species was mostly successful.
\end{abstract}

Keywords: Staphylococcus, Streptococcus, bovine mastitis, intergenic rRNA spacer

\section{INTRODUCTION}

Bovine mastitis is a multifactorial disease and is one of the most difficult to control. It can be caused by many different bacterial species, the most common of which are Staphylococcus and Streptococcus species. The prevalence of different species varies geographically, temporally and also due to control measures adopted in herds. In addition, different pathogens are typical of different types of mastitis (clinical, subclinical or heifer mastitis).

In many countries the most common bacterial species causing mastitis are Staphylococcus aureus, Streptococcus dysgalactiae and Streptococcus uberis (Aarestrup et al., 1995; Ministry of Agriculture and Forestry Mastitis Committee, 1989; Jonsson et al., 1991). Streptococcus agalactiae was previously the most common, but due to the use of antibiotic therapy its prevalence has decreased in many countries (Bramley $\&$ Dodd, 1984). The importance of coagulase-negative staphylococci (CNS) as pathogenic agents has been under discussion

Abbreviations: ATC-PCR, Air Thermo-Cycler PCR; CNS, coagulase-negative staphylococci.

The GenBank accession numbers for the sequences reported in this paper are U39765-U39773, U39813-U39814 and U90010-U90027.
(Kloos \& Bannermann, 1994). CNS are part of normal skin flora and have previously been regarded only as minor pathogens. However, the proportion of CNS mastitis has increased markedly during the last decade (Myllys et al., 1994). The most frequently isolated CNS species include Staphylococcus hyicus, Staphylococcus simulans, Staphylococcus epidermidis, Staphylococcus chromogenes and Staphylococcus xylosus (Harmon \& Langlois, 1989; Jarp, 1991; Todhunter et al., 1993; Aarestrup et al., 1995; Honkanen-Buzalski et al., 1994).

The identification of pathogens causing mastitis is important for disease control and epidemiological studies. In a clinical laboratory this is done using traditional microbiological methods (Klastrup \& Schmidt Madsen, 1974). The species determination usually takes at least $24 \mathrm{~h}$. There are no rapid and cheap methods available for the classification of CNS to the species level and therefore CNS species are usually determined only at the group level. There are commercial biochemical kits available for the determination of CNS species (e.g. API-Staph, Staph-Ident, StaphTrac, Staph-Zym) but they have proved unreliable for the identification of veterinary pathogens (Watts \& Yancey, 1994).

The development of molecular biological methods, such as nucleic acid analysis, protein patterns or fatty acid 
profiles, has added possibilities for the rapid identification of bacteria (Busse et al., 1996). Species-specific DNA sequences can be used for the identification of bacterial species. The 16S-23S rRNA intergenic spacer of the ribosomal RNA operon $(r r n)$ has proven useful for identification of strains and species (Barry et al., 1991; Jensen et al., 1993; Gürtler \& Stanisich, 1996). The spacer region is considered non-functional and is consequently argued to be under minimal selective pressure (Barry et al., 1991). Its evolutionary rate is 10 times greater than that of $16 \mathrm{~S}$ rDNA (Leblond-Bourget et al., 1996), the sequence of which is routinely used for phylogenetic studies of bacteria (Ludwig \& Schleifer, 1994). The high evolutionary rate makes it possible to distinguish closely related bacterial species.

The aims of this study were to determine the sequences of the 16S-23S rRNA intergenic spacers from the most common staphylococcal and streptococcal bovine mastitis pathogens and to investigate the possibility of designing species-specific oligonucleotide primers from the spacer sequences for the rapid identification of these bacterial species.

\section{METHODS}

Bacterial strains and culture conditions. All bacterial species and strains used in this study (Table 1 ) were grown aerobically in Tryptic Soy Broth (Difco) at $37^{\circ} \mathrm{C}$. Most of the specificity control species (Table 2) were obtained as cultures on agar plates or as DNA. The rest of the control species (e.g. all Lactobacillus species) were grown as recommended in the ATCC catalogue. Mastitic milk samples were obtained from the Food and Environmental Laboratory, Oulu, Finland and from the National Veterinary and Food Research Institute (EELA), Helsinki, Finland. Milk samples were cultivated overnight on M17 (Difco) agar plates at $37^{\circ} \mathrm{C}$. The total bacterial mass was harvested for DNA isolation. For PCR sensitivity tests, Sta. aureus DNA was isolated directly from mastitic milk according to the method described by Hynes et al. (1992).
Bacterial DNA isolation and amplification of spacer region. Genomic DNA was isolated by the method of Anderson \& McKay (1983) with modifications described by Steenson \& Klaenhammer (1985). Oligonucleotide primers used for amplifying the 16S-23S rRNA intergenic spacer region were selected from the conserved regions at the $3^{\prime}$ end of the $16 \mathrm{~S}$ rRNA and the $5^{\prime}$ end of the $23 \mathrm{~S}$ rRNA genes. The sequences of the primers were 5' GTCGGAATCGCTAGTAATCG 3' for 16$1 \mathrm{~A}$ (bases 1333-1352 in the Escherichia coli 16S rDNA sequence, A14565) and 5' GGGTTCCCCCATTCGGA 3' for 23-1B (bases 130-114 in the E. coli 23S rDNA sequence, A14566). PCR was performed in a DNA thermal cycler 480 (Perkin-Elmer) with a DyNAzyme DNA Polymerase Kit (Finnzymes). A typical reaction mixture $(50 \mu \mathrm{l})$ consisted of reaction buffer $(10 \mathrm{mM}$ Tris $/ \mathrm{HCl}, \mathrm{pH} 8.8,1.5 \mathrm{mM} \mathrm{MgCl}$, $50 \mathrm{mM} \mathrm{KCl}, 0 \cdot 1 \%$ Triton X-100), $200 \mu \mathrm{M}$ each dNTP, $1 \mu \mathrm{M}$ 16-1A and $23-1 \mathrm{~B}$ primers, $5 \mathrm{ng}$ bacterial DNA and $0.5 \mathrm{U}$ DyNAzyme DNA polymerase. The reaction mixtures were overlaid with mineral oil (Sigma), incubated at $92^{\circ} \mathrm{C}$ for $2 \mathrm{~min}$, then subjected to 30 cycles of $95^{\circ} \mathrm{C}$ for $30 \mathrm{~s}, 55^{\circ} \mathrm{C}$ for $30 \mathrm{~s}, 72^{\circ} \mathrm{C}$ for $30 \mathrm{~s}$. Amplification products were analysed on $1.5 \%(\mathrm{w} / \mathrm{v})$ agarose gels.

Sequencing methods. PCR products from the spacer regions were sequenced directly by a cycle sequencing method using a CircumVent Thermal Cycle Dideoxy DNA Sequencing Kit (New England Biolabs). Sequencing reactions were performed using 15 cycles of $95^{\circ} \mathrm{C}$ for $40 \mathrm{~s}, 55^{\circ} \mathrm{C}$ for $30 \mathrm{~s}$ and $72^{\circ} \mathrm{C}$ for $2 \mathrm{~min}$. The oligonucleotide fragments produced were separated on polyacrylamide gels (Sequagel-6, National Diagnostics). Both strands of DNA were sequenced. If the sequencing was not performed using the total PCR products, the products were cloned into a TA-cloning vector (Original TA Cloning Kit, Invitrogen). Ten positive clones were selected from each species, and plasmid DNA was isolated by alkaline lysis-PEG precipitation (Sambrook et al., 1989). Inserts were sequenced using a CircumVent Thermal Cycle Dideoxy DNA Sequencing Kit or DNA Sequencing Kit for the ABI Prism automatic sequencer (Perkin Elmer).

Analysis of sequence data. The sequences were analysed with DNASIS version 7.0 (Hitachi), and with GCG version 6.0 (Devereux et al., 1984).

Table 1. Bacterial strains used for determination of 16S-23S rRNA spacer sequences

\begin{tabular}{|lcccc|}
\hline Species & Strain & $\begin{array}{c}\text { Length of } \\
\text { spacer (bp) }\end{array}$ & $\begin{array}{c}\text { tRNA in } \\
\text { spacer }\end{array}$ & GenBank accession no. \\
\hline Str. agalactiae & ATCC 27956 & 279 & Ala & U39765 \\
Str. dysgalactiae & ATCC 27957 & 285 & Ala & U39767 \\
Str. uberis & ATCC 27958 & 340 & Ala & U39768 \\
Sta. aureus & ATCC 25923 & 458 & Ile & U39769 \\
Sta. chromogenes & ATCC 43764 & 279 & - & U39770 \\
Sta. epidermidis & ATCC 12228 & $261-263$ & - & U39771, U90018-U90021 \\
Sta. hyicus & KNS 264/92 & $375-380$ & - & U39772, U90010-U90015 \\
Sta. simulans & ATCC 11631 & $240-242$ & - & U39813, U90022-U90027 \\
Sta. xylosus & & 333 & Ile & U39814 \\
\hline
\end{tabular}

* The ATCC strains were obtained from the American Type Culture Collection, Rockville, MD, USA and the KNS strain was obtained from EELA, National Veterinary and Food Research Institute, Helsinki, Finland. 
Table 2. Bacterial strains used for assessing the specificity of primers

\begin{tabular}{|c|c|c|}
\hline Species & Strain & PCR products* \\
\hline Actinomyces pyogenes & Isolated from mastitic milk $\neq$ & STAX (150 bp-2.8 kb) \\
\hline Bacillus cereus & Isolated from mastitic milk $\ddagger$ & - \\
\hline Corynebacterium bovis & EMO-M/18-I-17 & $\begin{array}{l}\text { STRA }(1.5 \mathrm{~kb}) \\
\text { STAS }(2.4 \mathrm{~kb})\end{array}$ \\
\hline Enterobacter cloacae & Isolated from mastitic milk $\ddagger$ & - \\
\hline Enterococcus sp. & Isolated from mastitic milk $\ddagger$ & STR \\
\hline Escherichia coli & Isolated from mastitic milk $\ddagger$ & STAX $(200 \mathrm{bp}-1.6 \mathrm{~kb})$ \\
\hline Klebsiella oxytoca & Isolated from mastitic milk $\ddagger$ & - \\
\hline Klebsiella pneumoniae & Isolated from mastitic milk $\neq$ & - \\
\hline Lactobacillus acidophilus & ATCC 4356 & - \\
\hline Lactobacillus casei & ATCC 27092 & - \\
\hline Lactobacillus delbrueckii & ATCC 15808 & - \\
\hline Lactobacillus belveticus & ATCC 15009 & - \\
\hline Lactococcus lactis & F7/2 industrial starter strain & - \\
\hline $\begin{array}{l}\text { Leptospira borgpetersenii serovar } \\
\text { hardjo subtype hardjobovis } \dagger\end{array}$ & Clinical isolate & - \\
\hline Micrococcus varians & Isolated from mastitic milk $\neq$ & STAX (500 bp-1 kb) \\
\hline Mycoplasma bovis & Donetta & STAH $(240 \mathrm{bp})$ \\
\hline Nocardia brasiliensis & HAMBI 1960 & - \\
\hline Peptococcus indolicus & AHC 14990‡ & - \\
\hline Propionibacterium freudenreichii & ATCC 6207 & - \\
\hline Pseudomonas aeruginosa & Isolated from mastitic milk $\ddagger$ & - \\
\hline Str. bovis & ATCC 27960 & STR \\
\hline Str. thermophilus & ATCC 19987 & STR \\
\hline Str. zooepidemicus & EMO-M/18-III-63‡ & STR \\
\hline
\end{tabular}

* The DNA of these strains were tested with STAA, STAC, STAE, STAH, STAS, STAX, STRA, STRD, STRU, STA and STR primer pairs (Table 4). Primer pairs which yielded a PCR product are indicated. † The subtype was determined by restriction endonuclease digestion of genomic DNA.

¥ Strains isolated from mastitic milk were obtained from EELA, National Veterinary and Food Research Institute, Helsinki, Finland where the species was determined.

PCR with species-specific primers. Based on the comparison of the nucleotide sequences of the spacers, specific primers were designed for each of the species. Genus-specific primers for the Staphylococcus and Streptococcus species included in this study were also constructed. The PCR reactions were carried out as above using optimized $\mathrm{MgCl}_{2}$ concentrations for each primer pair (see Table 4). A rapid new generation thermal cycler, Air Thermo-Cycler (ATC, Idaho Technology), was also tested for amplification with the specific primer pairs. ATC-PCR uses glass capillary tubes instead of microcentrifuge tubes, which are incubated at $94^{\circ} \mathrm{C}$ for $15 \mathrm{~s}$, then 30 cycles of $94^{\circ} \mathrm{C}$ for $0 \mathrm{~s}, 55^{\circ} \mathrm{C}$ for $0 \mathrm{~s}$ and $72^{\circ} \mathrm{C}$ for $15 \mathrm{~s}$. This program takes a total of $15 \mathrm{~min}$ instead of $2 \mathrm{~h}$ using a conventional thermocycler. The reaction buffers included $0 \cdot 25 \mu \mathrm{g} \mathrm{BSA} \mathrm{m}^{-1}$. The $\mathrm{MgCl}_{2}$ concentrations used in ATC-PCR are listed in Table 4.

\section{RESULTS AND DISCUSSION}

\section{Amplification of the spacer region for sequencing}

Primers complementary to conserved sequences near the $3^{\prime}$ end of the $16 \mathrm{~S}$ and the $5^{\prime}$ end of the $23 \mathrm{~S}$ rRNA genes were used to amplify the $16 \mathrm{~S}-23 \mathrm{~S}$ spacer from nine species which commonly cause mastitis. In staphylococcal species more than one PCR product was detected, although in all cases one band predominated. It is known that the bacterial genome can contain several rrn operons, e.g. Sta. aureus has nine operons (Gürtler \& Barrie, 1995). The size of the main band differed between species. The weaker bands may also represent heteroduplex molecules resulting from cross-hybridization of amplification products from different kinds of operons (Jensen \& Straus, 1993).

\section{Sequencing the spacer regions from total PCR products}

The 16S-23S spacer region from streptococcal species and Sta. chromogenes could be sequenced directly from the PCR products. This indicated that there was a low level of sequence variation in the rrn operons within these species. Only the spacer sequence of Sta. chromogenes contained a variable nucleotide site (marked $S$ at position 331 in Fig. 1a), with both $G$ and $C$ detected at this position. The previously published spacer sequence 
of Str. agalactiae (GenBank accession no. L31412; Hall et al., 1995) was compared to our Str. agalactiae sequence and only one insertion/deletion and one substitution were found (positions 98 and 351 in Fig. 1a). Sequencing of the spacer region from Sta. aureus, Sta. epidermidis, Sta. byicus, Sta. simulans and Sta. xylosus gave multiple sequences that could not be read, suggesting the presence of insertions and/or deletions in the 16S-23S spacer regions of different $r r n$ operons. The purification of the main PCR product from agarose gels for sequencing did not improve the readability of sequences, possibly because the insertions and/or deletions were too small to cause sufficient length variation in the spacers. The aligned nucleotide sequences of the spacer regions of streptococcal species are shown in Fig. 1 (b) and the spacer region of Sta. chromogenes is shown in Fig. 1(a).

\section{Sequencing the spacer regions from plasmid clones}

The PCR products from the spacer regions of Sta. aureus, Sta. epidermidis, Sta. byicus, Sta. simulans and Sta. xylosus were cloned into TA-cloning vector. Ten clones from different PCR amplifications were sequenced from Sta. epidermidis, Sta. byicus, Sta. simulans and Sta. xylosus. Several different spacer sequences were obtained: five from Sta. epidermidis, seven from Sta. hyicus, eight from Sta. simulans and two from Sta. xylosus (Fig. 1a, clone types A-H). Most of the differences between the sequences from a single strain were single base insertions/deletions and substitutions. Given that the rate of artefactual misincorporation during PCR is relatively low and random, it is likely that these differences represent mutations present in the genome. The first sequence shown for each species (Fig. 1a) was obtained from clones from two independent amplifications. Some substitutions and insertions/ deletions of tRNA genes were also found. All the streptococcal species had a tRNA-Ala gene in the spacer and Sta. aureus, Sta. byicus and Sta. simulans had a tRNA-Ile gene in some of their rrn-operons (Fig. 1, Table 1). In general, however, the sequence variation within species was very low. From Sta. aureus only one clone was sequenced, since the sequences of all Sta. aureus $r r n$ operons have been published previously by Gürtler \& Barrie (1995). Our cloned Sta. aureus spacer sequence was $99 \%$ homologous to the allele $r r n F$ (GenBank accession no. U11779; Gürtler \& Barrie, 1995), with only three single base insertions/deletions and four mismatches.

\section{Sequence variation between species}

The pairwise sequence identities between 16S-23S spacer sequences of different species were calculated using the DNA Maximum Homology program of DNASIs (Table 3 ). This program favours short deletions over long ones and may overestimate the influence of a long deletion on the degree of DNA identity. The sequence identity between species within a genus varied from 53 to $85 \%$. The calculated sequence identities between species of different genera were about $50 \%$, but because gaps were used freely, this is an overestimate. The sequences were aligned manually in Fig. 1(a) and (b) to minimize the number of sequence differences. The spacer sequences for Str. bovis (GenBank accession no. U39766; this study) and Str. thermophilus (U32965; Tilsala-Timisjärvi \& Alatossava, 1997) were included in the alignment (Fig. 1b) to obtain more information about the variation of the spacer regions within the Streptococcus genus. This knowledge was important for the design of species-specific primers. The amount of sequence difference between staphylococci and streptococci prevented their reliable alignment. The only regions of sequence similarity ( $\geqslant 8 \mathrm{bp}$ ) between these two genera have been indicated in the alignments (Fig. $1 \mathrm{a}$ and $\mathrm{b}$ ). Both conserved regions are important for RNA processing (Chiaruttini \& Milet, 1993). When com paring the species within genera, the $3^{\prime}$ terminal third of the spacer region was found to be highly variable and difficult to align, especially in staphylococcal species. The $5^{\prime}$ terminus was more conserved (Fig. 1).

\section{Design of primer pairs from the species-specific sequence regions}

The variation between the $165-23 \mathrm{~S}$ spacer sequences of different mastitis pathogens made it possible to design specific primer pairs for each of the nine species considered in this study. The oligonucleotides were selected near the ends of the spacer region (Fig. 1, Table 4). In addition, primer pairs for Staphylococcus and Streptococcus were designed (Fig. 1, Table 4). The primer pairs were selected so that the same PCR cycling conditions could be employed for all of them. The optimum $\mathrm{MgCl}_{2}$ concentrations were adjusted for both conventional PCR (Perkin-Elmer 480) and ATC-PCR (Table 4). There was some sequence variation within species at the primer regions. In those cases the primers were selected from the most common spacer type. Species-specific PCR primers have been published previously for some of the species (although not for strains isolated from cases of bovine mastitis) from the $16 \mathrm{~S}$ rRNA gene, e.g. Sta. aureus and Sta. epidermidis (Saruta et al., 1995; Gribaldo et al., 1997).

\section{Sensitivity of the primers}

Products were detected using as little as $50 \mathrm{pg}$ purified bacterial DNA, with 35 cycles in PCR. The DNA concentrations were measured with a spectrophotometer (Gene Quant II, Pharmacia Biotech) and with a fluorometer (TKO100 Mini-Fluorometer, Hoefer Scientific). When the sensitivity of the primers was estimated by isolating DNA directly without cultivation from mastitic milk samples containing Sta. aureus, a $1 \mu \mathrm{lmilk}$ sample containing 40 c.f.u. yielded a PCR product (results not shown). 
(a)

$\begin{array}{llllllllll}1 & 10 & 20 & 30 & 40 & 50 & 60 & 70 \quad 80 & 90\end{array}$

U11779 AAGGATA-TA TTCGGAACAT CTTCTTCAGA AGATG----C GGAATAACG- -TGACATATT GTATTCAGTT TTGAATGTTT ATTT----AA CATTCAAA--

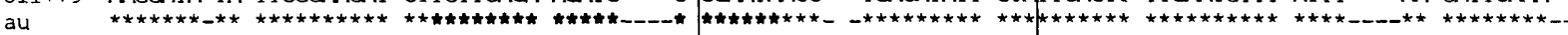

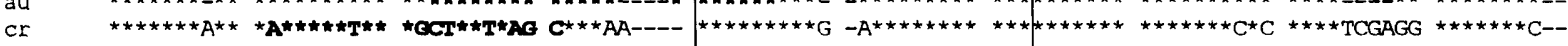

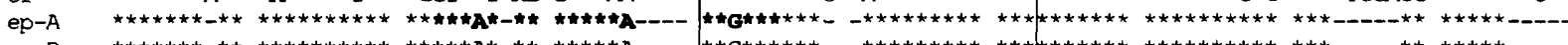

ep-B

ep-C

ep-D

ep-E

hy-A

hy-B

hy-C

hy-D

hy-E

hy-E

hy-G

si-A

si-B

Si-C

si-D

Si-E

$S i-E$

Si-G

si-H

$x y-A$

$x y-B$

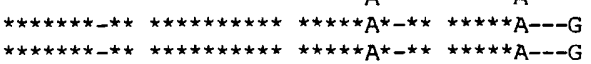

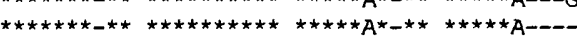

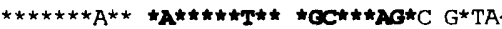

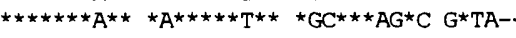

$\star \star \star \star \star \star \star \star A A^{\star \star \star} \star A^{\star \star \star \star \star \star *} T^{\star \star \star} \star G^{*} C^{\star \star \star} A G^{\star} \mathrm{C} G \mathrm{G}^{\star} \mathrm{TA}-$

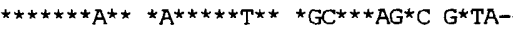

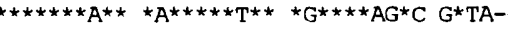

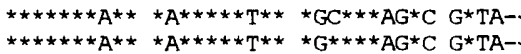

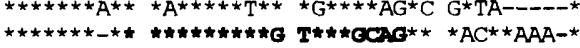

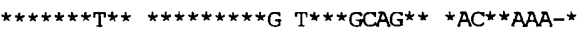

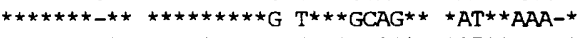

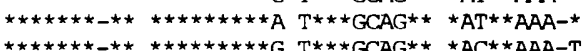

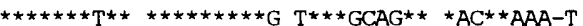

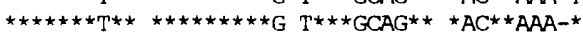

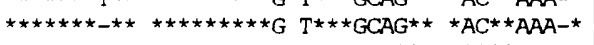

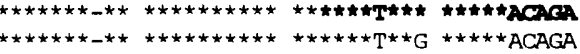

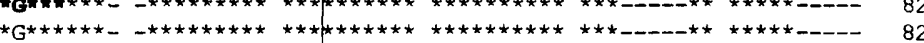

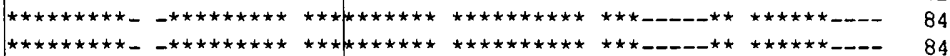

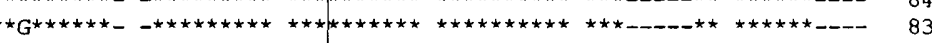

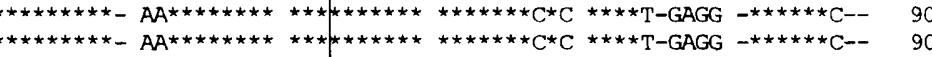

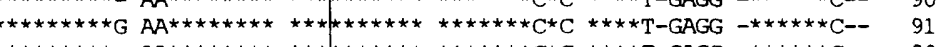

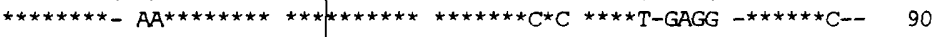

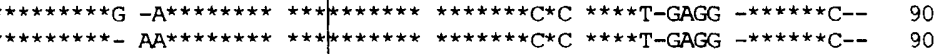

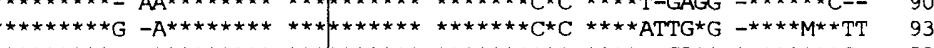

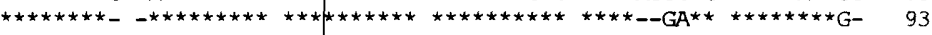

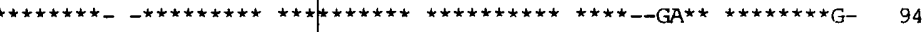

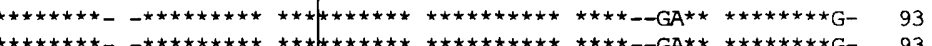

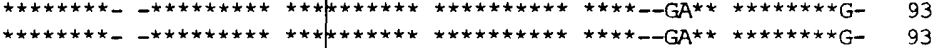

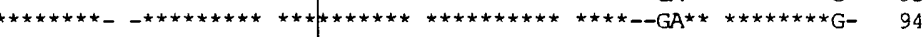

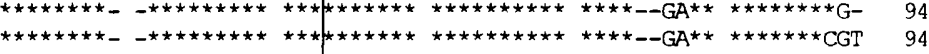

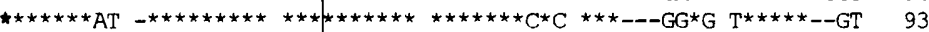

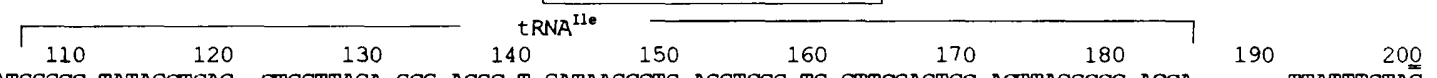

U11779 AAAATGGGCC TATAGCTCAG -CTGGTTAGA GCG-ACGC-T GATAAGCGTG AGGTCGG-TG GTTCGAGTCC ACTTAGGCCC ACCA- $190 \quad 200$

au $\quad$ at*

cr

ep-A

ep-B

ep-C

ep-D

ep-E

hy-A

hy-B

hy-c

hy-D

hy-E

hy-F

hy-G

si-A

si-B

si-C

Si-D

Si-E

Si-E

Si-G

$\mathrm{si}-\mathrm{H}$

$x y-A$

$x y-B$

U11779

au

cr

ep-A

ep-B

ep-C

ep-D

ep-E

hy-A

hy-B

hy-C

hy-D

hy-E

hy-E

hy-G

si-A

si-B

si-C

Si-D

si-E

Si-F

Si-G

$\mathrm{Si}-\mathrm{H}$

$x y-A$
$x y-B$

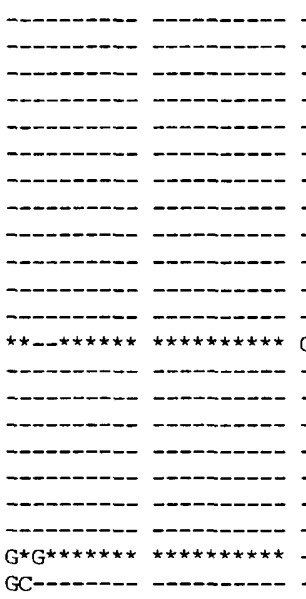

-
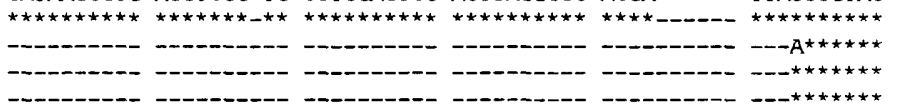

- - -

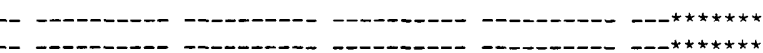

- - - - - - -

- - -

- -1-

-

- $-\cdots$

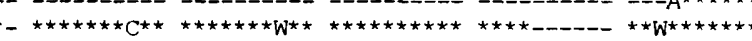

-

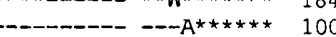

$--\cdots---A^{\star \star \star \star * \star * \star} 101$

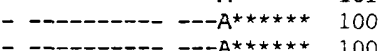

$\begin{array}{llll} & 100 \\ - & -10 & \end{array}$

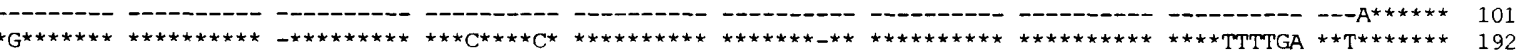

GC-

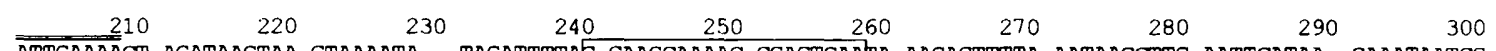

ATTGAAAACT AGATAAGTAA GTAAAATA-- TAGATTTTAE CAAGCAAAAC CGAGTGAATA AAGAGTTTTA AATAAGCTTG AATTCATAA- GAAATAATCG 383

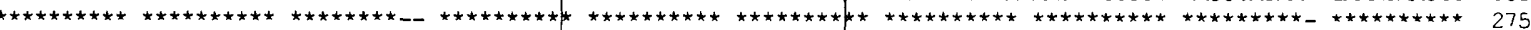

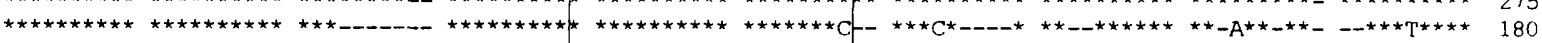

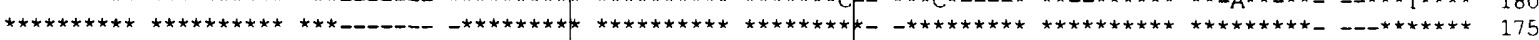

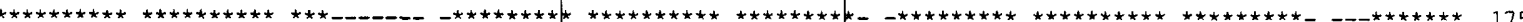

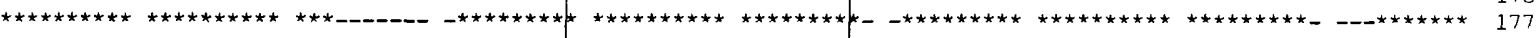

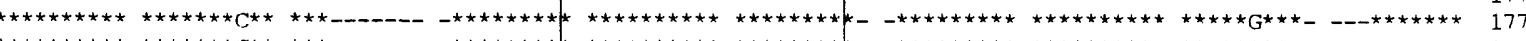

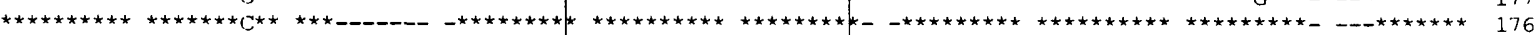

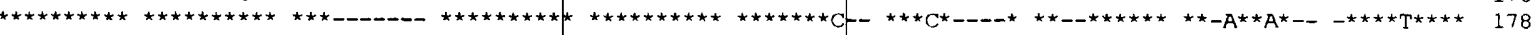

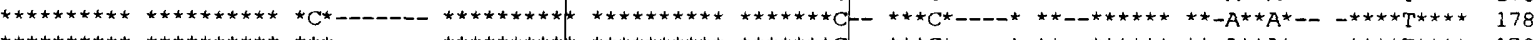

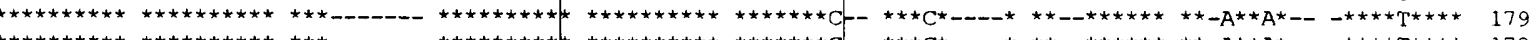

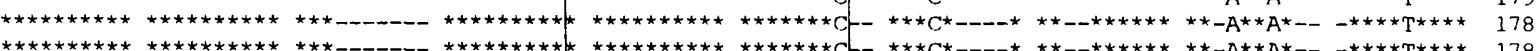

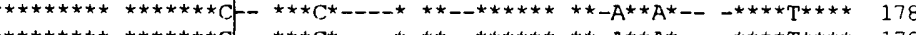

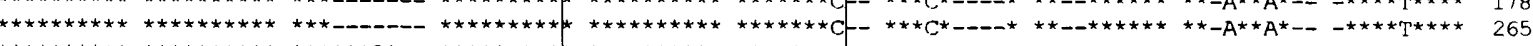

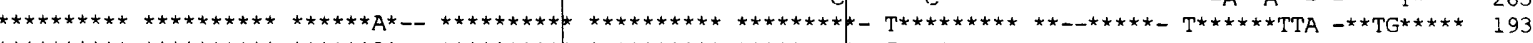

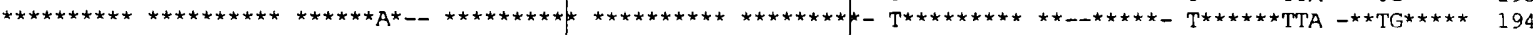

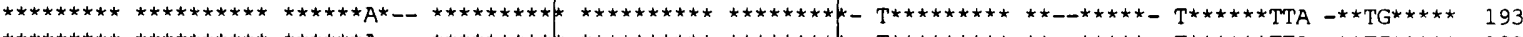

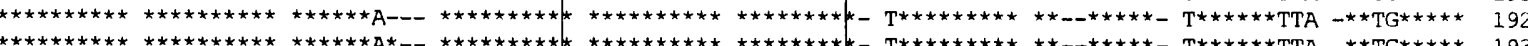

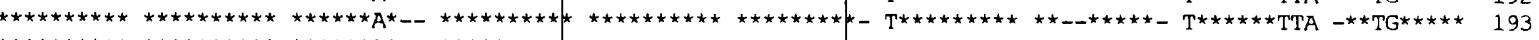

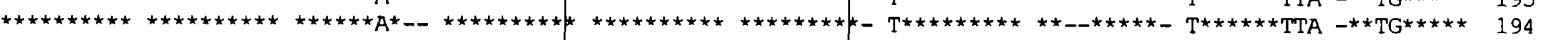

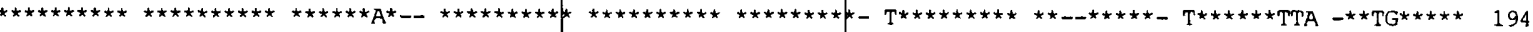

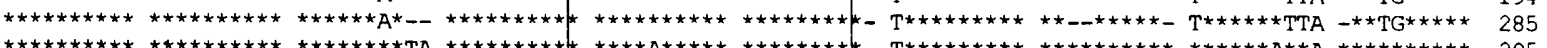

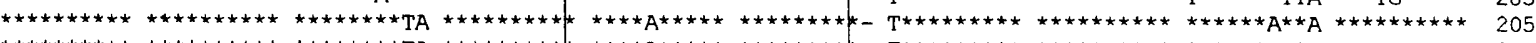

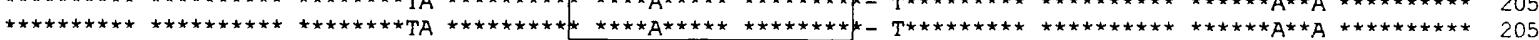

Fig. 1. For legend see page 3497 


\begin{tabular}{|c|c|c|c|c|c|c|c|c|c|c|c|}
\hline & 0 & 320 & 330 & 340 & 350 & 360 & 370 & 380 & 390 & 400 & \\
\hline & C-TAGTGTTC & $-\infty-\infty-\infty$ & - GAAAGAA & САCTCACAAG & TTAATAAC & GTGTTTAAAT & C------TTT & TTATAAAA-- & $-\infty-$ & $------G$ & \\
\hline & & & & & だォだ & & & & & & \\
\hline $\mathrm{cr}$ & $\star-\star \star \star \star C^{\prime} G^{\star \star}$ & --- & $---\star \star C^{\star} \star \star \star C C$ & 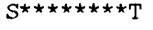 & $\star A * * \star \star \star * \star * * *$ & $\mathrm{TG}^{\star *} \mathrm{GG}^{\star} \mathrm{TG}^{\star}$ & TGGTTAT*G* & $\star \star \star$ ATTCCA- & - & - & 45 \\
\hline ep-A & $\star C^{\star \star \star \star \star \star ~}$ & -- & 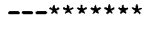 & 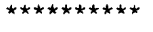 & 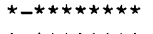 & $T A * * * * T * G C$ & TATTTA $-\star \star \star ~$ & $\star \star \star A T * \star C A-$ & $=-$ & --- & 39 \\
\hline$-B$ & 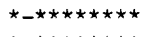 & ---- & 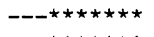 & $\star \star \star \star \star \star \star \star \star C^{\star}$ & 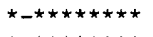 & $T A \star \star \star \star T \star G C$ & 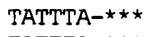 & $\star \star \star A T * \star C A-$ & -- & --- & 38 \\
\hline$b-C$ & 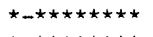 & ---- & 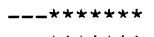 & 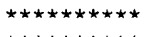 & 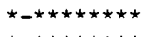 & $T A \star \star \star \star T^{\star}$ GC & 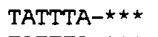 & $\star \star \star A T \star \star C A-$ & & $-\cdots$ & 40 \\
\hline$e p-D$ & 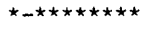 & ----- & 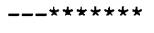 & 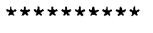 & 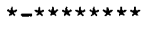 & $T A \star \star \star \star T \star T G C$ & 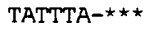 & $\star \star \star A T \star \star C A-$ & & -------- & ( \\
\hline$e p-E$ & 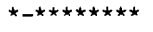 & $-\infty---$ & 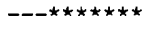 & 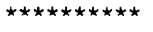 & 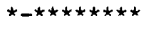 & $T A \star \star \star \star T \star G C$ & TATTTA $-\star \star \star$ & $\star \star * A T * * \mathrm{CA}-$ & & $---m-\infty$ & 39 \\
\hline$y-A$ & $-\star \star \star \star \mathrm{CG}^{\star} \star$ & $m-\infty$ & $---\star \star C^{\star \star \star \star} \mathrm{C}$ & $\mathrm{G}^{\star \star \star \star \star \star \star \star \star \star \star ~}$ & 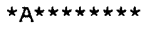 & $T G \star \star G G \star T G \star$ & TGGTTAA*G* & $\star \star \star \operatorname{CHTCO} \star A$ & Texcreater & $T-\cdots-T^{\star}$ & \\
\hline$y-B$ & $-\star \star \star \star \star C G \star \star$ & - & $\cdots \star \cdots C^{\star} \star \star C C$ & $\mathrm{G} \star \star \star \star \star \star \star \star \star T \mathrm{~T}$ & 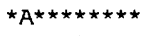 & $T G \star \star G G \star T G \star$ & $T G G T T A A \star G \star$ & $\star \star \star C^{T T C G} \star A$ & TGACAGATGT & $\mathrm{T}-\cdots--\mathrm{TT}^{*} \mathrm{~T}^{*}$ & \\
\hline$-C$ & $-\star \star \star \star \star C G * \star$ & --ー-ー-ー-ー- & $---\star \star C^{\star *} \mathrm{NC}$ & $G \star \star \star \star \star \star * \star * * T$ & 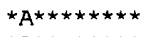 & ${ }^{\star} G G^{\star T} T G^{\star}$ & TGGTTAA ${ }^{\star} \mathrm{G}^{\star}$ & $\star \star \star C^{C T T C G} \star A$ & TGACAGATGT & $\mathrm{T}------\mathrm{TT}^{\star}$ & \\
\hline$y-D$ & $-\star \star \star \star C^{\prime} G \star \star$ & - - - & $-\cdots \star-C^{\star} \star N C$ & 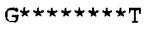 & $\star A * \star * \star \star \star \star \star * \star$ & $\star G_{G} * T G \star$ & $T T A A^{\star} G^{\star}$ & $\star \star \star$ CTTCG $^{\star} \mathrm{A}$ & ATGT & $\mathrm{T}------\mathrm{TT}^{\star}$ & \\
\hline$y-\mathrm{E}$ & $-\star \star \star \star \mathrm{CG}^{\star} \star{ }^{\prime}$ & -ー-ー-ー-ー-ー & $---\star \star G \star \star \star * \star C C$ & 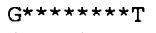 & 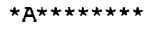 & $\star G G \star T G G$ & $A G \star G C$ & $A \star \star \star G^{*} T * T A$ & ATAA & GAATT* & \\
\hline$y-F$ & $-\star \star \star \star \star C G \star \star$ & ------- & 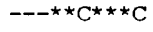 & $\mathrm{G} * \star \star \star \star \star \star \star \star \top \mathrm{T}$ & 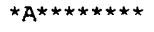 & $\star G G \star T G G$ & $A G \star G C$ & $A \star \star \star G T T \star T A$ & CGATAA & ACGTGAATT* & 64 \\
\hline$y-G$ & $-\star \star \star \star \star C G \star \star$ & $----\infty-\infty-1$ & 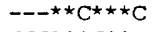 & 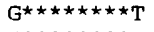 & 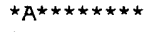 & $T G \star \star G G \star T G \star$ & $T T A A \star G \star$ & $\star \star \star$ CTTCG $* A$ & TGACAGATGT & $\mathrm{T}-----ー \mathrm{TT}^{\star}$ & 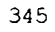 \\
\hline$i-A$ & 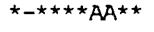 & AATTGCOGAC & $\operatorname{Cec} A * C^{\prime} \star * T$ & $T \star \hbar \star \star \star \star \star \star \star * ⿻ T 丨$ & 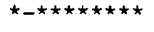 & ------- & & - - - & --ー-- & --ー-ー- - & 241 \\
\hline$-B$ & $-\star \star \star \star \star A A \star \star$ & DCGAC & $G C A \star \star C \star \star T$ & $\star \star \star \star \star \star \star \star \star \star T T$ & 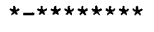 & --------- & & ---------- & ----- & ----ー----- & 42 \\
\hline$-C$ & 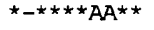 & CCGAC & $G C A \star \star C \star \star T$ & $\star \star \star \star \star \star \star \star \star \star T T$ & 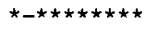 & --------- & --- & --ー-ー----- & $---\infty$ & - - - - - & 1 \\
\hline$-D$ & $-\star \star \star \star A A A^{\star \star}$ & AATT & $\star \mathrm{C}^{\star} \star \mathrm{T}$ & $\star \star \star \star \star \star \star \star \star \star T \mathrm{~T}$ & 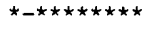 & --- & --- & $\cdots$ & --- & --n-n- & 10 \\
\hline$-E$ & $-\star \star \star \star \star A A^{\star \star}$ & CGAC & ${ }^{\star} \mathrm{C} \star \star T$ & $\star \star \star \star \star \star \star \star \star T T$ & 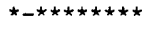 & 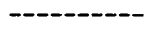 & --- & ---- & ------ & & 1 \\
\hline$-F$ & $-\star \star \star \star \star A A * \star$ & $G A C$ & $\star C \star * T$ & $\star \star \star \star \star \star \star \star \star * T$ & 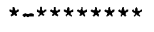 & --- ------ & --- & - & ------ & & 2 \\
\hline & $-\star \star \star \star A A \star \star \star$ & $\mathrm{AC}$ & ${ }^{*} C^{\star \star} \mathrm{T}$ & $\star \star \star \star \star T$ & 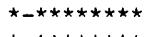 & - - - - - - & - & -- & -- & & 242 \\
\hline$\cdots$ & $-\star \star \star \star \star A A^{\star \star}$ & GAC & $\star C^{\star \star * T}$ & $\mathrm{~T} \star \star \star \star \star \star \star \star \star \star T \mathrm{~T}$ & 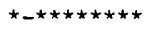 & --ー-ー----- & --- & --- & ----- & - & 3 \\
\hline$y-A$ & 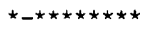 & -------- & 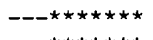 & 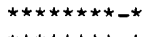 & 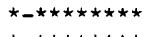 & $--A^{\star \star \star \star}---\star \star$ & 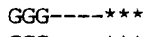 & $\star \star \star A--$ & ---- & & 4 \\
\hline \multirow[t]{2}{*}{$x y-B$} & 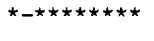 & 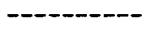 & 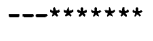 & & $\star \star \star \star \star * \star *$ & $--A^{\star \star \star *---\star \star ~}$ & GGG- - - *** & $\star \star \star A--$ & $-\cdots-\cdots$ & & \\
\hline & 410 & & & 440 & 450 & 460 & 470 & & & 500 & \\
\hline & AAACGTTTA & ATG & ATTA & AGCA & "TACTT & AAATGA & TAAAA & AAAA- & CGTA & SCGTT & 0 \\
\hline & 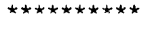 & 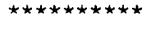 & $\star \star \star \star$ & $\star \star \star$ & $\star \star \star \star$ & $\star \star \star$ & $\star \star \star \star \star$ & & $\star \star \star \star \star$ & $A \star \star \star \star$ & 32 \\
\hline & ------- & $---\infty-\infty$ & --ー-ー--- & - - - & - - - - - - & ----ー----- & & - & 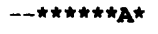 & $\mathbf{A}^{\star} \star A^{\star}$ & 63 \\
\hline$D-A$ & --n-- & $-\infty-\infty-\infty-\infty$ & ---- & -ーー-ーー-ー-ー & -------- & - - & -ー---ー- & & & & 39 \\
\hline$-B$ & -------- & ------- & - & $-\infty-\infty+\infty$ & ---n-- & -ー-ー-ー- & 年 & & & --- & 38 \\
\hline$-C$ & - & $\cdots+\cdots$ & n- & $+\infty+\infty-\infty$ & - & ------ & 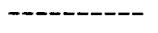 & & 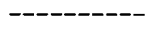 & -ー-ー-ー-ー- & 40 \\
\hline -D & - - - - - & $---2-2-1$ & --- & $-\infty-\infty-\infty-\infty$ & - - - - - - & --ー-ー----- & - - - - - & --ー-ー-ー-ー- & ------ & --- - - & 40 \\
\hline$-E$ & - & $-\cdots$ & --- & $--\infty$ & --------- & ---------- & -- - & - & ------ & $-\infty-\cdots$ & 39 \\
\hline$-A$ & $\star \star \star \star G$ & 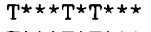 & $\because A A C$ & AAG & 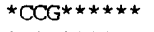 & $\mathrm{CC}^{\star \star \star \star} \mathrm{GCA}^{\star}$ & $\star G \star T T$ & $\star^{*} \mathrm{GT}$ & $\star \star \star A^{\star}$ & $\star \star \star A *$ & 8 \\
\hline$-B$ & $\star \star \star \star \star \star \star \star \star G$ & $\mathrm{~T}^{\star \star \star} \mathrm{T}^{\star} \mathrm{T}^{\star \star \star}$ & *AAC & AAG & $\star \star \star \star \star \star \star$ & $\star \star \star \star G C A \star$ & $C T G A G^{\star} G \star T T$ & * GTGCCGCGA & $\star \star \star A \star$ & $\star \star A^{\star}$ & 8 \\
\hline$-\mathrm{C}$ & $\star \star \star \star \star \star \star \star \star G$ & $T^{\star \star \star} T^{\star} T^{\star \star \star}$ & *AAC & $\triangle A G$ & $\star \star \star \star \star \star$ & $\star \star \star \star G C A \star$ & $\mathrm{G}^{\star} \mathrm{TT}$ & *GTGCCGCGA & $\star \star \star A \star$ & $\star \star \star A \star$ & 9 \\
\hline$-D$ & $\star \star \star \star \star \star \star \star \star ~ G$ & $\mathrm{~T}^{\star \star \star} \mathrm{T}^{\star} \mathrm{T}^{\star \star \star}$ & $* A A C$ & AAG & 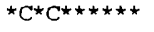 & $T^{\star \star \star \star \star \star} G^{\star} A^{\star}$ & $\mathrm{CG} G^{\star} \mathrm{TT}$ & CGCGA & $\star \star A^{\star}$ & $\star \star \star A \star$ & 8 \\
\hline$-E$ & $\star G^{\star \star \star \star \star \star} G$ & $T^{\star \star \star} T^{\star} T^{\star \star \star}$ & $\star A A C$ & AAG & $\star \star \star \star \star$ & $T^{\star \star \star \star \star \star} \mathrm{G}^{\star} A^{\star}$ & $C G \star T T$ & CCGTGA & $\star A^{\star} A^{\star}$ & $A^{\star} C^{\star}$ & 364 \\
\hline$-E$ & $\star \star \star \star \star \star \star \star \star G G$ & 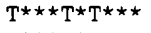 & AAC & VAG & $\star \star \star \star \star \star$ & $\star \star \star$ GCA $\star$ & ${ }^{\star} G \star T T$ & CGCGA & $\star \star \star A^{\star}$ & $\star \star \star A^{\star}$ & 363 \\
\hline$r-G$ & $\star \star \star \star \star \star \star * \star G G$ & $\mathrm{~T}^{\star \star \star \star} \mathrm{T}^{\star} \mathrm{T} \mathrm{T}^{\star \star \star}$ & $\star A A C$ & ZAAG & 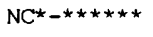 & $\mathrm{CC} \star \star \star \star \mathrm{RCA}^{\star}$ & ${ }^{\star} G^{\star} T T$ & CGCGA & $N^{\star \star} A^{\star}$ & $\star \star \star A^{\star}$ & 4 \\
\hline$-A$ & $-m$ & ---- & ---- & -- & --- & ----- & --- & --- & --- & ------ & 1 \\
\hline- & ------- & - & --- & $-\infty$ & $-\cdots$ & $-\infty$ & & & & $---\infty$ & 42 \\
\hline$-\mathrm{C}$ & -n- & - & --- & -- & --- & --- & & -- & -- & ---- & 1 \\
\hline$-D$ & ------- & --- & $--\infty$ & -- & -- & ----- & & & & $-\infty$ & 10 \\
\hline$-E$ & --n-- & - & --- & $-\infty$ & 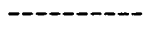 & $-\infty$ & - & & & --- & 41 \\
\hline$-E$ & ---n-- & $-\infty-\infty$ & --O-n- & - & --- & $--\infty$ & & & - & --- & 42 \\
\hline$-G$ & ------- & -- & ---- & ---- & -- & ---- & & & & ---- & 42 \\
\hline 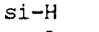 & -- - - - - & $--\infty-\infty$ & --------- & -ーーーーーーーーー & -- & --- & & $\cdots$ & - - - - - & -ー-ー-ー- & 333 \\
\hline$y-A$ & $-\infty-\infty$ & $--\infty-\infty$ & ----- & - - - - & -- & $-\cdots$ & & 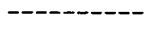 & $-----\star \star \star A C$ & $\star-\star \operatorname{Cog} T \star \star \star G$ & 268 \\
\hline$y^{-B}$ & thents & $-\infty$ & $\cdots$ & 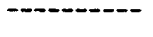 & 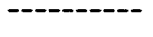 & $--x_{2}$ & & & $--\infty \star \star \star \star$ & 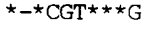 & 68 \\
\hline & & & & & & & & & & & \\
\hline
\end{tabular}

U11779 TGACTTATAA AAATGGTGGA AACATA 566

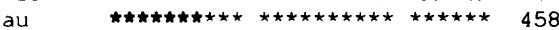

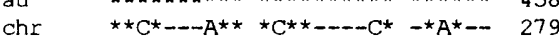

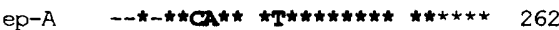

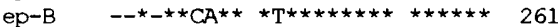

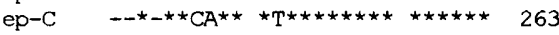

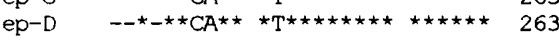

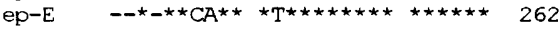

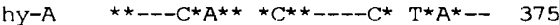

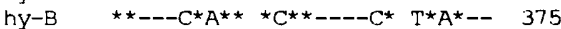

hy $-C \quad \star \star---C^{\star} A^{\star \star} \star C^{\star \star} C^{\star}----C^{\star} T^{\star} A^{\star}--\quad 376$

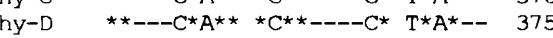

hy-E $\quad \star A T-C C^{\star A} A-C * C G * T T A \quad 378$

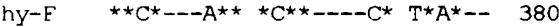

hy $-G \quad \star \star C^{\star}---A^{\star \star} \star \star C^{\star \star}---C^{\star} T^{\star} A^{\star}--461$

Si-A ---------- ---------- ------ 241

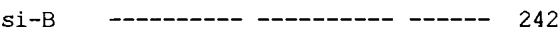

Si-C -

Si-D - - -

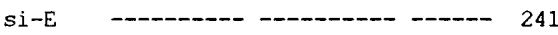

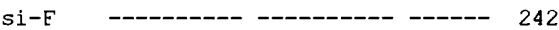

SI-G --

si-H -

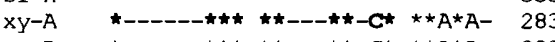

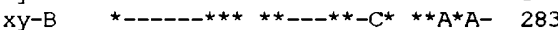

Fig. 1. For legend see facing page. 
16S-23S rRNA spacer sequences of bovine mastitis pathogens

(b)

(b)
L31412
ag
dy
ub
th
bo

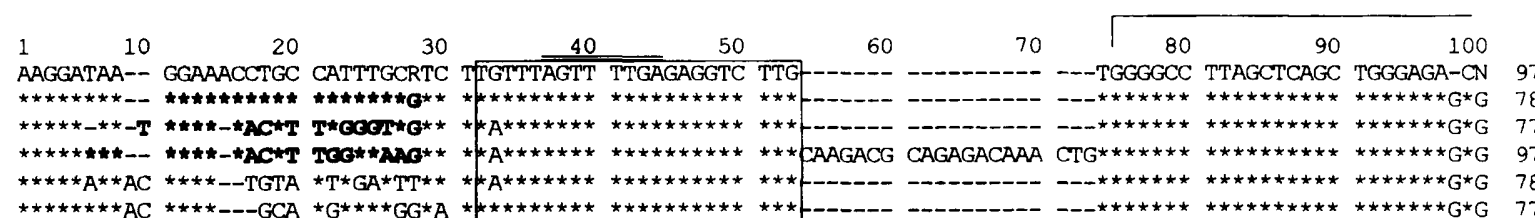

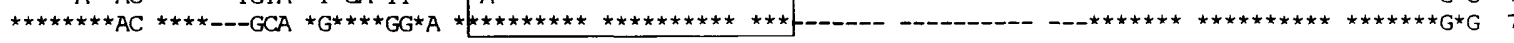
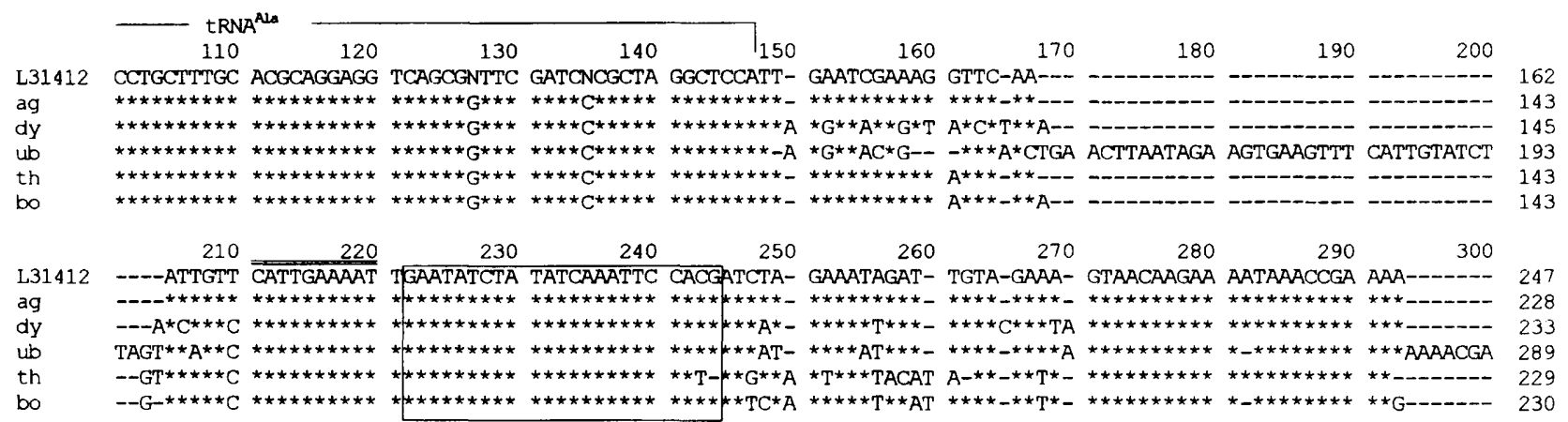

bo

310

330

340

350

360

L31412 ---CGCTGT GAA--TATTT AATGAGTTTT -CTAGTTTTA AAGAAACTAG TTTAA--TAA 298

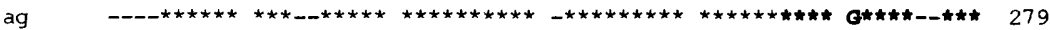

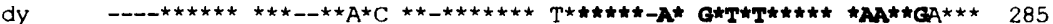

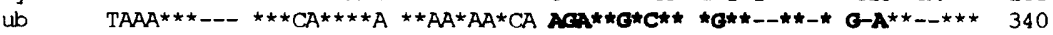

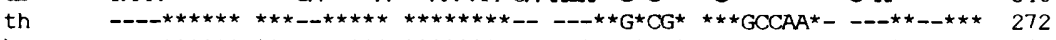

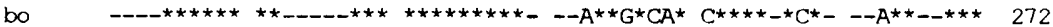

Fig. 1. Alignments of the $16 \mathrm{~S}-23 \mathrm{~S}$ intergenic spacer sequences from (a) staphylococcal species and (b) streptococcal species. Symbols: au, Sta. aureus; cr, Sta. chromogenes; ep, Sta. epidermidis; hy, Sta. hyicus; si, Sta. simulans; xy, Sta. xylosus; ag, Str. agalactiae; dy, Str. dysgalactiae; ub, Str. uberis; th, Str. thermophilus (GenBank accession no. U32965; Tilsala-Timisjarvi \& Alatossava, 1997); bo, Str. bovis (U39766; this study). The clone types are indicated after the species in capital letters (A-H). U11779 and L31412 are the spacer sequences of Sta. aureus and Str. agalactiae, respectively (Gurtler \& Barrie, 1995; Hall et al., 1995). The species-specific primers are presented in bold, and the genus-specific primers are boxed. The regions (minimum length $8 \mathrm{bp}$ ) identical in all staphylococcal and streptococcal species are indicated with double lines. Identical nucleotides are indicated with asterisks, deletions with dashed lines, and transitions and transversions compared to the uppermost sequence of the alignment are indicated with capital letters. The locations of tRNA genes are indicated above the aligned sequences.

\section{Specificity of the primers}

Each primer pair was tested at least twice with DNA from 31 different bacterial species (Tables 1 and 2) using $5 \mathrm{ng}$ template DNA in a $20 \mu \mathrm{l}$ PCR reaction with conventional PCR. Appropriate controls were included in PCR; a positive control for DNA and primers and a negative control for PCR mix. In addition, the primer pairs were tested after raising the concentration of DNA from staphylococcal and streptococcal species up to $100 \mathrm{ng}$ in a $20 \mu \mathrm{l}$ PCR reaction. The performance of ATC-PCR was tested with nine DNA samples (Table 1). The 'species-specific' primer pairs (Table 4) amplified their targets mainly as expected, amplifying only the corresponding DNA (Table 2, Fig. 2). The unexpected products with STAX, STRA, STAH and STAS primer pairs differed in size from the expected products, and no amplification with the 'genus-specific' primers was observed. If these cases represented true Streptococcus or Staphylococcus species, a product with the genusspecific primers would have been expected also. The genus-specific primers amplified as expected: the Staphylococcus specific primers amplified only staphylococcal DNA, and the Streptococcus specific primers amplified streptococcal, lactococcal and enterococcal
DNA (Table 2). Lactococci and enterococci are very closely related to streptococci and have similar sequences in the primer regions (Chiaruttini \& Milet, 1993; Sechi \& Daneo-Moore, 1993; Tilsala-Timisjärvi \& Alatossava, 1997; Wood \& Holzapfel, 1995).

\section{Validity of the primers with mastitis samples}

The original staphylococcal and streptococcal strains from which the spacer regions were sequenced were mostly ATCC strains (Table 1), not isolated from bovine mastitis. To investigate if there was sequence variation between strains within a species, which could affect the utility of the assays, we performed PCR on 51 isolates from cases of bovine mastitis. The conventional species determination was made in a veterinary clinical microbiology laboratory (Food and Environmental Laboratory, Oulu, Finland or National Veterinary and Food Research Institute Helsinki, Finland). PCR reactions used purified DNA from each cultivated isolate (Table 5). The staphylococcal genus-specific primer pair distinguished the genus with $100 \%$ sensitivity and specificity. The streptococcal genus-specific primer pair detected one Sta. aureus isolate and all streptococcal isolates. 
Table 3. Sequence identity between 16S-23S rDNA spacer sequences of different Staphylococcus and Streptococcus species

au, Sta. aureus clone; cr, Sta. chromogenes; ep-A, Sta. epidermidis clone type A; hy-A, Sta. hyicus clone type A; si-A, Sta. simulans clone type A; xy-A, Sta. xylosus clone type A; ag, Str. agalactiae; dy, Str. dysgalactiae; ub, Str. uberis.

\begin{tabular}{|cccccccccc|}
\hline \multicolumn{10}{|c|}{ DNA identity (\%)* } \\
\hline Spacer & cr & ep-A & hy-A & si-A & xy-A & ag & dy & ub \\
\hline au & 63 & 68 & 69 & 58 & 65 & 50 & 52 & 53 \\
cr & $\cdot$ & 74 & 71 & 66 & 70 & 52 & 54 & 52 \\
ep-A & & $\cdot$ & 59 & 71 & 77 & 52 & 52 & 52 \\
hy-A & & & $\cdot$ & 53 & 57 & 51 & 52 & 51 \\
si-A & & & & $\cdot$ & 71 & 51 & 51 & 50 \\
xy-A & & & & & $\cdot$ & 53 & 53 & 52 \\
ag & & & & & & $\cdot$ & 85 & 70 \\
dy & & & & & & & $\cdot$ & 70 \\
\hline
\end{tabular}

* The tRNA gene region was excluded from the Sta. aureus (au) spacer sequence for analysis. The calculations were made by the DNA Maximum Homology program of DNASIS.

Ninety percent of the isolates identified conventionally at the species level $(36 / 40)$ were recognized with the species-specific primers. The reason for the failure of

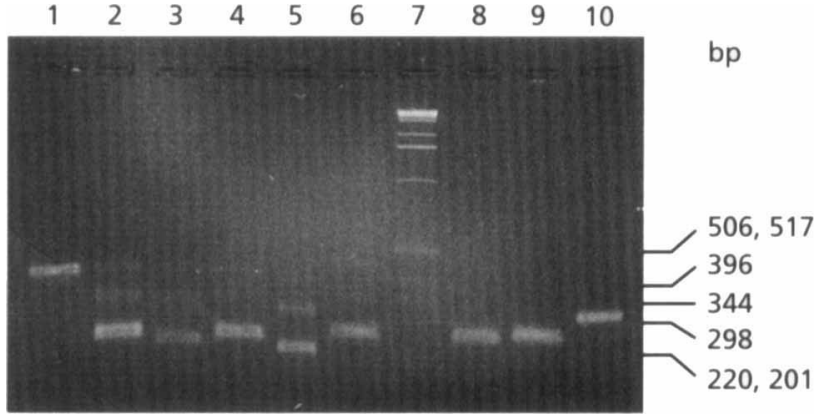

Fig. 2. The $P C R$ products from different streptococcal and staphylococcal species amplified with corresponding speciesspecific primer pairs. Lanes: 1 , Sta. aureus ATCC 25923; 2 , Sta. chromogenes ATCC 43764; 3, Sta. epidermidis ATCC 12228; 4, Sta. hyicus KNS 264/92; 5, Sta. simulans ATCC 11631; 6, Sta. xylosus ATCC 12162; 7, $1 \mathrm{~kb}$ ladder (Gibco BRL); 8, Str. agalactiae ATCC 27956; 9, Str. dysgalactiae ATCC 27957; 10, Str. uberis ATCC 27958.

identification for four isolates may be sequence variation between strains in the primer regions. In addition, three isolates gave a PCR product with a second speciesspecific primer pair (Table 5). These products may also be due to sequence variation. Alternatively, the milk samples may have contained minor amounts of these other bacterial species. Only five of the CNS isolates were identified to the species level in the clinical

Table 4. Species- and genus-specific oligonucleotide primers from the $16 \mathrm{~S}-23 \mathrm{~S}$ rRNA intergenic spacer region for bovine mastitis pathogens

\begin{tabular}{|c|c|c|c|c|c|c|}
\hline Species & Oligonucleotide* & Sequence $\left(5^{\prime}-3^{\prime}\right)$ & $\begin{array}{c}\text { Length } \\
\text { (nt) }\end{array}$ & $\begin{array}{c}\mathrm{MgCl}_{2} \text { in } \\
\mathrm{PCR} \\
(\mathrm{mM}) \dagger\end{array}$ & $\begin{array}{c}\mathrm{MgCl}_{2} \text { in } \\
\text { ATC-PCR } \\
(\mathbf{m M}) \dagger\end{array}$ & $\begin{array}{l}\text { Size of the } \\
\text { main PCR } \\
\text { product (bp) }\end{array}$ \\
\hline \multirow[t]{2}{*}{ Str. agalactiae } & STRA-AgI & GGAAACCTGCCATTGCG & 18 & $3 \cdot 0$ & $5 \cdot 0$ & 280 \\
\hline & STRA-AgII & TAACTTAACCTTATTAACCTAG & 22 & & & \\
\hline \multirow[t]{2}{*}{ Str. dysgalactiae } & STRD-DyI & TGGAACACGTTAGGGTCG & 18 & $3 \cdot 0$ & $3 \cdot 0$ & 270 \\
\hline & STRD-DyII & СTTTTACTAGTATATCTTAACTA & 23 & & & \\
\hline \multirow[t]{2}{*}{ Str. uberis } & STRU-UbI & TAAGGAACACGTTGGTTAAG & 20 & $1 \cdot 5$ & $3 \cdot 0$ & 330 \\
\hline & STRU-UbII & TCCAGTCCTTAGACCTTCT & 19 & & & \\
\hline \multirow{2}{*}{ Sta. aureus } & STAA-AuI & TCTTCAGAAGATGCGGAATA & 20 & $2 \cdot 0$ & $3 \cdot 0$ & 420 \\
\hline & STAA-AuII & TAAGTCAAACGTTAACATACG & 21 & & & \\
\hline \multirow[t]{2}{*}{ Sta. chromogenes } & STAC-ChrI & ACGGAATATCGCTTTTAAGC & 20 & $1 \cdot 5$ & $3 \cdot 0$ & 250 \\
\hline & STAC-ChrII & CGTTTACATTCGGCTTTCG & 19 & & & \\
\hline \multirow[t]{2}{*}{ Sta. epidermidis } & STAE-EpI & TCTACGAAGATGAGGGATA & 19 & $3 \cdot 0$ & $3 \cdot 0$ & 240 \\
\hline & STAE-EpII & TTTCCACCATATTTTGAATTGT & 22 & & & \\
\hline \multirow[t]{2}{*}{ Sta. byicus } & STAH-HyI & TACGGAATATCGCCTTAGG & 19 & $1 \cdot 5$ & $4 \cdot 0$ & 250 \\
\hline & STAH-HyII & AAAACATCTGTCATCCGAAG & 20 & & & \\
\hline \multirow[t]{2}{*}{ Sta. simulans } & STAS-SiI & ATTCGGAACAGTTTCGCAG & 19 & $1 \cdot 5$ & $4 \cdot 0$ & 220 \\
\hline & STAS-SiII & ATTGTGAGTAATCGTTTGCC & 20 & & & \\
\hline \multirow[t]{2}{*}{ Sta. xylosus } & STAX-XyI & TCTTTAGAAGATGACAGAGG & 20 & $1 \cdot 5$ & $3 \cdot 0$ & 260 \\
\hline & STAX-XYII & TGACTTTTAACACGACGAAG & 20 & & & \\
\hline \multirow[t]{2}{*}{ Streptococcus genus } & STR I & TGTTTAGTTTTGAGAGGTCTTG & 22 & $1 \cdot 5$ & $5 \cdot 0$ & $150-210$ \\
\hline & STR II & CGTGGAATTTGATATAGATATTC & 23 & & & \\
\hline \multirow{2}{*}{ Staphylococcus genus } & STA I & GGAATAACGTGACATATTGTA & 21 & 1.5 & $3 \cdot 0$ & $100-200$ \\
\hline & STA II & TTCACTCGGTTTTGCTTGG & 19 & & & \\
\hline
\end{tabular}

*Primer I in each primer pair is from the $5^{\prime}$ terminus of the spacer and primer II is from the $3^{\prime}$ terminus of the spacer.

† Optimal $\mathrm{MgCl}_{2}$ concentrations in PCR reactions. 
16S-23S rRNA spacer sequences of bovine mastitis pathogens

Table 5. Specificity of the primer pairs with DNA of 51 isolates from mastitic milk

\begin{tabular}{|c|c|c|}
\hline Bacterial sample & No. of samples & Identification with PCR \\
\hline Sta. aureus & 19 & Staphylococcus, Sta. aureus \\
\hline Sta. aureus & 2 & Staphylococcus \\
\hline Sta. aureus & 1 & Staphylococcus, Sta. aureus, Streptococcus \\
\hline Sta. aureus & 2 & Staphylococcus, Sta. aureus, Str. agalactiae \\
\hline Sta. aureus & 1 & Staphylococcus, Sta. aureus, Sta. hyicus \\
\hline Sta. chromogenes* & 1 & Staphylococcus, Sta. chromogenes \\
\hline Sta. epidermidis* & 1 & Staphylococcus, Sta. epidermidis \\
\hline Sta. byicus* & 1 & Staphylococcus, Sta. byicus \\
\hline Sta. simulans* & 1 & Staphylococcus, Sta. simulans \\
\hline Sta. $x y$ losus & 1 & Staphylococcus \\
\hline CNS & 1 & Staphylococcus, Sta. chromogenes \\
\hline CNS & 3 & Staphylococcus, Sta. simulans \\
\hline CNS & 4 & Staphylococcus, Sta. xylosus \\
\hline CNS & 3 & Staphylococcus \\
\hline Str. uberis & 5 & Streptococcus, Str. uberis \\
\hline Str. uberis & 1 & Streptococcus, Str. uberis, Str. agalactiae \\
\hline Str. agalactiae & 2 & Streptococcus, Str. agalactiae \\
\hline Str. dysgalactiae & 1 & Streptococcus, Str. dysgalactiae \\
\hline Str. dysgalactiae & 1 & Streptococcus \\
\hline
\end{tabular}

* CNS samples identified at the species level.

laboratories (Table 5). Eight out of eleven CNS samples $(73 \%)$ were detected by PCR with the species-specific primers. With the API-Staph system we identified one of the remaining CNS samples as Staphylococcus warneri, which could not be detected with our PCR primers. Two other CNS samples remain unidentified.

\section{Applicability of the results}

The important aims of this study were to investigate the level of sequence variation in the $16 \mathrm{~S}-23 \mathrm{~S}$ spacer region between different staphylococcal and streptococcal mastitis pathogens and the potential use of this variation for the rapid identification of these pathogens to species level. The conventional microbiological and biochemical methods for identifying mastitis pathogens are timeconsuming. In addition, CNS species are still difficult to identify, and thus species identification is not done routinely, in spite of their increased prevalence in mastitis cases (White et al., 1989; Myllys et al., 1994). The advantages of PCR compared to other diagnostic methods are rapidity and facility. Furthermore, screening for antibiotic resistance could be combined with PCR-based species identification. In practice, the PCR identification could be done in two stages. First, performing the tests for the genus (STA, STR), Sta. aureus, the streptococcal species and antibiotic resistance (e.g. blaZ for $\beta$-lactamase gene). The second PCR would be the identification of CNS species if necessary. The main disadvantage of a PCR identification method might be excessive sensitivity, with minor contaminants in samples resulting in misdiagnosis. The multiple copy number of $r r n$ operons in a bacterial genome is an advantage, increasing the sensitivity of PCR, but the potential for variation within a species may reduce the sensitivity for all strains. The current primer pairs work reasonably well, but not yet with $100 \%$ of isolates. Improvement in both primer design and PCR conditions is still needed. The primer pairs designed in this study proved to be specific and appropriately sensitive, such that the normal bacterial flora in milk did not give PCR products. However, a more extensive study of sequence variation in strains of these species isolated from cases of bovine mastitis is still needed to critically assess specificity. The traditional species identification would have to be confirmed by sequencing part(s) of the $16 \mathrm{~S}$ rRNA gene, since even biochemical identification systems are not $100 \%$ reliable. Our future work will focus on detecting mastitic pathogens by PCR directly from milk.

\section{ACKNOWLEDGEMENTS}

We thank Professor Tuula Honkanen-Buzalski from the National Veterinary and Food Research Institute, Helsinki, Finland and Taito Palo and Eija Eskola from the Food and Environmental Laboratory, Oulu, Finland for collaboration and mastitic milk samples, Associate Professor Satu Pyörälä, University of Helsinki, Helsinki, Finland and the Anaerobic Laboratory in the National Public Health Institute, Helsinki, Finland for Peptococcus indolicus strains, Professor Karl-Erik Johansson from the National Veterinary Institute, Uppsala, Sweden for providing Mycoplasma bovis DNA and Dr Roger Marshall, Massey University, Palmerston North, New Zealand for providing Leptospira borgpetersenii serovar hardjo subtype hardjobovis DNA. 


\section{REFERENCES}

Aarestrup, F. M., Wegener, H. C., Rosdahl, V. T. \& Jensen, N. E. (1995). Staphylococcal and other bacterial species associated with intramammary infections in Danish dairy herds. Acta Vet Scand 36, 475-487.

Anderson, D. G. \& McKay, L. L. (1983). Simple and rapid method for isolating large plasmid DNA from lactic streptococci. Appl Environ Microbiol 46, 549-552.

Barry, T., Colleran, G., Glennon, M., Dunican, L. K. \& Gannon, F. (1991). The $16 S / 23 S$ ribosomal spacer region as a target for DNA probes to identify Eubacteria. PCR Methods Appl 1, 51-56.

Bramley, A. J. \& Dodd, F. H. (1984). Reviews of the progress of dairy science: mastitis control - progress and prospects. J Dairy Sci 51, 481-512.

Busse, H.-J., Denner, E. B. M. \& Lubitz, W. (1996). Classification and identification of bacteria: current approaches to an old problem. Overview of methods used in bacterial systematics. J Biotechnol 47, 3-38.

Chiaruttini, C. \& Milet, M. (1993). Gene organization, primary structure and RNA processing analyses of a ribosomal RNA operon in Lactococcus lactis. J Mol Biol 230, 57-76.

Devereux, J., Haeberli, P. \& Smithies, O. (1984). A comprehensive set of sequence analysis programs for VAX and Convex systems. Nucleic Acids Res 12, 387-395.

Gribaldo, S., Cookson, B., Saunders, N., Marples, R. \& Stanley, J. (1997). Rapid identification by specific PCR of coagulase-negative staphylococcal species important in hospital infection. J Med Microbiol 46, 45-53.

Gürtler, V. \& Barrie, H. D. (1995). Typing of Staphylococcus aureus strains by PCR-amplification of variable length $16 \mathrm{~S}-23 \mathrm{~S}$ rDNA spacer regions: characterization of spacer sequences. Microbiology 141, 1255-1265.

Gürtler, V. \& Stanisich, V. A. (1996). New approaches to typing and identification of bacteria using the $16 \mathrm{~S}-23 \mathrm{~S}$ rDNA spacer region. Microbiology 142, 3-16.

Hall, L. M. C., Duke, B. \& Urwin, G. (1995). An approach to the identification of the pathogens of bacterial meningitis by the polymerase chain reaction. Eur J Clin Microbiol Infect Dis 14, 1090-1094.

Harmon, R. J. \& Langlois, B. E. (1989). Mastitis due to coagulasenegative Staphylococcus species. Agri-Practice 10, 29-34.

Honkanen-Buzalski, T., Myllys, V. \& Pyörălä, S. (1994). Bovine clinical mastitis due to coagulase-negative staphylococci and their susceptibility to antimicrobials. J Vet Med B 41, 344-350.

Hynes, W. L., Ferretti, J. J., Gilmore, M. S. \& Segarra, R. A. (1992). PCR amplification of streptococcal DNA using crude cell lysates. FEMS Microbiol Lett 94, 139-142.

Jarp, J. (1991). Classification of coagulase-negative staphylococci isolated from bovine clinical and subclinical mastitis. Vet Microbiol 27, 151-158.

Jensen, M. A. \& Straus, N. (1993). Effect of PCR-conditions on the formation of heteroduplex and single-stranded DNA products in the amplification of bacterial ribosomal DNA spacer regions. PCR Methods Appl 3, 186-194.

Jensen, M. A., Webster, J. A. \& Straus, N. (1993). Rapid identification of bacteria on the basis of polymerase chain reactionamplified ribosomal DNA spacer polymorphisms. Appl Environ Microbiol 59, 945-952.
Jonsson, P., Olsson, S.-O., Olofson, A.-S., Fälth, C., Holmberg, 0. \& Funke, H. (1991). Bacteriological investigations of clinical mastitis in heifers in Sweden. J Dairy Res 58, 179-185.

Klastrup, O. \& Schmidt Madsen, P. (1974). Scandinavian recommendations on examination of quarter milk samples. Nordisk Veterinaermed 26, 197-204.

Kloos, W. E. \& Bannermann, T. L. (1994). Update on significance of coagulase-negative staphylococci. Clin Microbiol Rev 7, 117-140.

Leblond-Bourget, N., Philippe, H., Mangin, I. \& Decaris, B. (1996). $16 \mathrm{~S}$ rRNA and $16 \mathrm{~S}$ to $23 \mathrm{~S}$ internal transcribed spacer sequence analyses reveal inter- and intraspecific Bifidobacterium phylogeny. Int J Syst Bacteriol 46, 102-111.

Ludwig, W. \& Schleifer, K. H. (1994). Bacterial phylogeny based on $16 \mathrm{~S}$ and $23 \mathrm{~S}$ rRNA sequence analysis. FEMS Microbiol Rev 15, 155-173.

Ministry of Agriculture \& Forestry Mastitis Committee (1989). Prevention of Mastitis. Memo no. 19/1989, Ministry of Agriculture and Forestry, Helsinki, Finland.

Myllys, V., Honkanen Buzalski, T., Huovinen, P., Sandholm, M. \& Nurmi, E. (1994). Association of changes in the bacterial ecology of bovine mastitis with changes in the use of milking machines and antibacterial drugs. Acta Vet Scand 35, 329-335.

Sambrook, J., Fritsch, E. F. \& Maniatis, T. (1989). Molecular Cloning: a Laboratory Manual, 2nd edn. Cold Spring Harbor, NY: Cold Spring Harbor Laboratory.

Saruta, K., Hoshina, S. \& Machida, K. (1995). Genetic identification of Staphylococcus aureus by polymerase chain reaction using single-base-pair mismatch in $16 \mathrm{~S}$ ribosomal RNA gene. Microbiol Immunol 39, 839-844.

Sechi, L. \& Daneo-Moore, L. (1993). Characterization of intergenic spacers in two rrn operons of Enterococcus hirae ATCC 9790. J Bacteriol 175, 3213-3219.

Steenson, L. R. \& Klaenhammer, T. R. (1985). Streptococcus cremoris $\mathrm{M} 12 \mathrm{R}$ transconjugants carrying the conjugal plasmid pTR2030 are insensitive to attack by lytic bacteriophages. $A p p l$ Environ Microbiol 50, 851-858.

Tilsala-Timisjarrvi, A. \& Alatossava, T. (1997). Development of oligonucleotide primers from the 16S-23S rRNA intergenic sequences for identifying different dairy and probiotic lactic acid bacteria by PCR. Int J Food Microbiol 35, 49-56.

Todhunter, D. A., Cantwell, L. L., Smith, K. L., Hoblet, K. H. \& Hogan, J. S. (1993). Characteristics of coagulase-negative staphylococci isolated from bovine intramammary infections. Vet Microbiol 34, 373-380.

Watts, J. L. \& Yancey, R. J., Jr (1994). Identification of veterinary pathogens by use of commercial identification systems and new trends in antimicrobial susceptibility testing of veterinary pathogens. Clin Microbiol Rev 7, 346-356.

White, D. G., Harmon, R. J., Matos, J. E. S. \& Langlois, B. E. (1989). Isolation and identification of coagulase-negative Staphylococcus species from bovine body sites and streak canals of nulliparous heifers. J Dairy Sci 72, 1886-1892.

Wood, B. J. B. \& Holzapfel, W. H. N. (1995). Genera of Lactic Acid Bacteria. Glasgow: Blackie Academic \& Professional.

Received 3 March 1997; revised 23 June 1997; accepted 21 July 1997. 